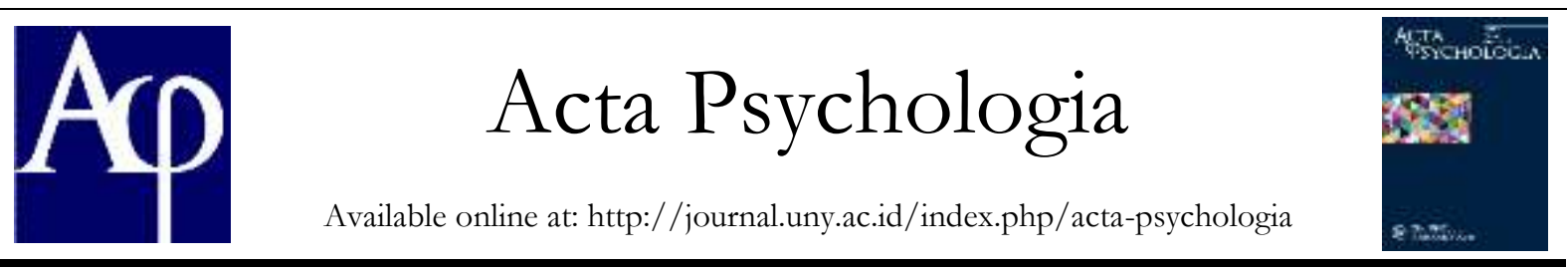

\title{
Fear of Missing Out dan Kesejahteraan Psikologis Individu Pengguna Media Sosial di Usia Emerging Adulthood
}

\author{
Judithya Anggita Savitri \\ Jurusan Psikologi, Fakultas Ilmu Pendidikan, Universitas Negeri Yogyakarta; \\ Jl. Colombo No. 1 Sleman Yogyakarta, 55281 \\ judithyaa98@gmail.com
}

\begin{abstract}
Abstrak
Penelitian ini bertujuan untuk mencari tahu pengaruh Fear of Missing Out (FoMO) terhadap kesejahteraan psikologis terutama pada pengguna media sosial di usia emerging adulthood. Penelitian ini menggunakan pendekatan kuantitatif dengan jenis penelitian korelasional. Penelitian dilakukan di provinsi DIY melalui link googleform. Sampel dalam penelitian ini berjumlah 400 orang yang didapatkan dengan metode accidental sampling. Alat pengumpulan data menggunakan skala fear of missing out (FoMO) dan skala kesejahteraan psikologis yang telah dimodifikasi dari skala FoMO milik Przybylski dan skala kesejahteraan milik Ryff. Skala FoMO memiliki pernyataan sebanyak 15 butir dengan koefisien reliabilitas $\alpha=0,849$ dan skala kesejahteraan psikologis memiliki 45 butir pernyataan dengan koefisien reliabilitas $\alpha=0,941$. Teknik analisis data menggunakan uji regresi linier sederhana. Hasil penelitian menunjukkan bahwa FoMO mampu memprediksi kesejahteraan psikologis $(\beta=0,315, \mathrm{~F}(1,398)=43,753$; $\mathrm{p}<0,001)$. FoMO dapat memprediksi kesejahteraan psikologis dengan nilai kontribusi sebesar 9,9\% $\left(\mathrm{R}^{2}=0,099\right.$, $\mathrm{p}<0,001)$.
\end{abstract}

Kata Kunci: fear of missing out, FoMO, kesejabteraan psikologis, emerging adulthood

\begin{abstract}
This study aimed to find out the impact of FoMO on psychological well-being especially for social media users at the age of emerging adulthood. This study used a quantitative correlational research. The research was conducted in the DIY and the data collected through googleform link. The sample in this study amounted to 400 people obtained by the accidental sampling method. The data collected using a fear of missing out (FoMO) scale and a psychological well-being scale that had been modified from Przybylski's FoMO scale and Ryff's Psychological wellbeing scale. The FoMO scale has total of 15 items with a reliability coefficient $\alpha=0.849$ and the psychological wellbeing scale has 45 items with a reliability coefficient $\alpha=0.941$. The data analysis technique used the simple linear regression test. The result of this study showed that FoMO was able to predict psychological well-being $(\beta=0.315$, $\mathrm{F}(1.398)=43.753 ; \mathrm{p}<0.001)$. FoMO can predict psychological well-being with a contribution value of $9,99\left(\mathrm{R}^{2}=\right.$ $0.099, \mathrm{p}<0.001)$.
\end{abstract}

Keywords: fear of missing out, FoMO, psychological well-being, emerging adulthood

\section{Pendahuluan}

Kesejahteraan psikologis adalah salah satu hal yang didambakan oleh semua orang. Ryff (1995) mengatakan bahwa kesejahteraan psikologis adalah kemampuan seseorang untuk mengenal dan mengembangkan diri sesuai dengan potensi yang dimiliki. Menurut Ryff (1989), seseorang dapat dikatakan memiliki kesejahteraan psikologis ketika orang tersebut dapat berfungsi positif secara psikologis. Ryff dan Singer (2008) mengatakan individu dengan kesejahteraan psikologis tinggi akan lebih produktif dan memiliki kesehatan mental maupun fisik yang lebih baik dibandingkan individu yang kesejahteraan psikologisnya rendah. 
Huppert (2009) juga menyatakan kesejahteraan psikologis berhubungan dengan pemikiran yang fleksibel dan kreatif, perilaku prososial, dan kesehatan yang baik.

Namun, berdasarkan data yang didapat dari World Health Organization (WHO) jumlah orang yang hidup dengan gangguan mental meningkat lebih dari 18\% antara tahun 2005 hingga tahun 2015. Didukung dengan pernyataan dari Kementerian Kesehatan Republik Indonesia (2016) yang mengatakan bahwa kesehatan jiwa masih menjadi salah satu permasalahan kesehatan yang signifikan di dunia, termasuk di Indonesia. Data Riset Kesehatan Dasar (riskesdas) tahun 2013 menunjukkan prevalensi gangguan mental emosional yang ditunjukkan dengan gejalagejala depresi dan kecemasan untuk usia 15 tahun ke atas mencapai sekitar 14 juta orang atau $6 \%$ dari jumlah penduduk Indonesia. Hal ini menjadi indikasi bahwa masih banyak individu yang memiliki kesejahteraan psikologis yang rendah.

Data yang diperoleh dari hasil survei Twenge (2018) menambahkan fakta bahwa sejak tahun 2008 hingga 2017, tingkat individu yang melaporkan gejala depresi meningkat sebanyak 63\% pada orang dewasa muda usia 18 hingga 25 tahun. Presentase orang dewasa muda yang mengalami tekanan psikologis serius juga meningkat sebanyak 71\%. Begitupula pada pikiran untuk bunuh diri pada orang dewasa muda meningkat sebanyak $47 \%$.

Salah satu faktor yang menyebabkan rendahnya kesejahteraan psikologis menurut Przybylski, Murayama, DeHaan, \& Gladwell (2013) yaitu Fear of Missing out atau biasa disebut FoMO. Beyens, Erison, \& Eggermont (2016) mendukung pernyataan Przybylski, dkk (2013) dengan mengatakan bahwa FoMO menjadi tanda bahwa kesejahteraan psikologis seseorang cenderung negatif. Dikatakan demikian karena perasaan takut, cemas, serta khawatir yang dihasilkan karena adanya FoMO membuat individu tidak mampu untuk menguasai lingkungan, menjalin relasi positif dengan orang lain, dan penerimaan diri yang rendah.

FoMO didefinisikan sebagai ketakutan seseorang akan kehilangan kesempatan sosial sehingga mendorong orang tersebut untuk selalu terhubung secara terus menerus dengan orang lain dan mengikuti berita terbaru tentang segala sesuatu yang dilakukan orang lain (Przybylski, dkk, 2013).

Perasaan takut, cemas, serta khawatir tersebut menyebabkan individu mengalami kesulitan dalam menguasai lingkungan, menjalin relasi positif dengan orang lain, dan menerima dirinya (Beyens, dkk, 2016). Studi menunjukkan bahwa orang yang menghadapi FoMO lebih mungkin terjerumus dalam tuntutan psikologis untuk tetap terhubung dan berhubungan dengan orang lain (Beyens, dkk, 2016). Partisipasi di media sosial menjadi menarik bagi mereka yang mengalami FoMO. Penelitian Przybylski, dkk (2013) menunjukkan hasil bahwa orang yang memiliki tingkat FoMO yang tinggi berada di usia yang lebih muda dan melaporkan mood yang lebih rendah dan kepuasan hidup yang lebih rendah pula. Pryzbylski, dkk (2013) menyatakan bahwa penderita FoMO lebih mungkin untuk memeriksa telepon genggamnya segera setelah mereka bangun tidur di pagi hari, tepat sebelum mereka pergi tidur, bahkan ketika mereka berkendara.

Fenomena FoMO sangat erat hubungannya dengan penggunaan media sosial di era digital. Pada era digital ini, sebagian besar orang tentu mengenal media sosial. Berkat adanya media sosial, komunikasi dapat terjalin tanpa berbatas jarak, waktu, maupun ruang. Media sosial menyediakan ruang bagi seseorang untuk berkomunikasi aktif dengan orang lain dan memudahkan individu dalam mengakses informasi baru (Burke, Marlow, \& Lento, 2010).

Media sosial didefinisikan sebagai layanan berbasis web yang memungkinkan penggunanya untuk menciptakan profil umum atau semi umum dalam suatu 
sistem; menampilkan pengguna lainnya yang berkaitan dengan dirinya; serta melihat dan mengamati daftar jaringan yang mereka miliki maupun daftar yang dibuat oleh pengguna lain dalam sistem tersebut (Boyd \& Ellison, 2008).

Pada masa kini, media sosial menarik perhatian orang-orang karena dapat digunakan sebagai sarana yang mudah dan penting untuk menjaga hubungan sosial serta untuk memuaskan kebutuhan sosial seseorang (Shapiro \& Margolin, 2014). Hal ini menyebabkan media sosial menjadi bagian yang tak terpisahkan dalam banyak hal dalam kehidupan (Lenhart, 2015).

Namun dibalik kepopuleran media sosial, ia juga memiliki berbagai dampak baik positif maupun negatif. Penggunaan media sosial yang bijak dan baik dapat menimbulkan dampak positif, misalnya kemudahan mendapatkan informasi kesehatan dari orang yang ahli; mendapatkan dukungan emosi; membentuk komunitas; dsb (Royal Society for Public Health, 2017). Sedangkan penggunaan media sosial yang maladaptif dapat memberikan dampak negatif. Menurut Oberst, Renau, Chamarro \& Carbonell (2016) penggunaan media sosial yang maladaptif dapat menimbulkan dampak negatif bagi kesejahteraan dan fungsi psikologis anak, remaja, dan dewasa awal. Sejalan dengan ini, Twenge (2018) juga mengatakan bahwa penggunaan media sosial kemungkinan adalah penyebab dari meningkatnya masalah kesehatan mental pada orang dewasa muda.

Mengenai tren penggunaan media sosial di Indonesia, menurut pernyataan sekretaris jenderal Asosiasi Penyelenggara Jasa Internet Indonesia (APJII) pada tahun 2017 Indonesia mengalami pertumbuhan pengguna internet sebesar $54.6 \%$. Konten internet yang paling banyak diakses adalah konten media sosial dimana tercatat ada $97.4 \%$ orang Indonesia yang mengakses media sosial ketika menggunakan internet (Sugiharto, 2016).

Pengguna media sosial berasal dari berbagai tahap usia, namun Sugiharto (2016) mengatakan bahwa pengguna internet di Indonesia didominasi oleh anak muda. Pada kategori usia 20-24 tahun ditemukan 22.3 juta jiwa pengguna internet yang sebagian besarnya mengakses media sosial ketika menggunakan internet. Dikutip dari liputan6.com, Asosiasi Penyelenggara Jasa internet Indonesia (APJII) merilis data yang menyatakan bahwa sebagian besar respondennya mengaku mengakses internet lebih dari enam jam setiap hari. Ada sekitar 55.39\% dari total responden yang setiap hari mengakses internet lebih dari enam jam. Sementara responden lain bervariasi mulai dari 2 hingga 6 jam sehari. Usia 20 hingga 24 tahun masuk ke dalam tahap usia yang disebut emerging adulthood. Pada tahap usia ini, untuk pertama kalinya individu menghadapi tujuan dan tugas baru yang melibatkan orang lain secara langsung, sehingga dalam tahap ini individu diharapkan bukan hanya mengembangkan dan mencapai tujuan pribadinya namun juga memulai proses perkembangan yang baru dengan berhubungan dengan orang lain (Salkind, 2006). Namun menurut hasil penelitian Azka, Firdaus \& Kurniadewi (2018), individu di usia emerging adulthood juga memiliki kerentanan tinggi terhadap ketergantungan media sosial karena cenderung kurang stabil dalam mengelola kebutuhan hidup, hubungan interpersonal, serta mengembangkan aspek afektif maupun kognitif. Sehingga, ketika individu mendapat kesulitan dalam proses perkembangannya, individu akan 'melarikan diri' melalui pemakaian media sosial yang intensif.

Berdasarkan uraian di atas, terlihat bahwa pada tahap emerging adulthood individu ditekankan untuk membangun hubungan yang positif dengan individu lain. Namun adanya kemungkinan bahwa individu emerging adulthood memakai media sosial secara intensif serta merasakan FoMO yang mana dapat menyebabkan rendahnya hubungan positif dengan orang lain memungkinkan hal ini turut 
memengaruhi kesejahteraan psikologis individu tersebut.

Hal-hal yang mendorong diadakannya penelitian ini adalah karena belum banyaknya penelitian mengenai FoMO serta penting bagi pengguna media sosial untuk mengetahui dampak dari fear of missing out yang banyak terjadi pada pengguna media sosial.

\section{Metode Penelitian}

\section{Jenis Penelitian}

Penelitian ini menggunakan pendekatan kuantitatif dengan jenis korelasional.

\section{Waktu dan Tempat Penelitian}

Penelitian ini dilakukan pada bulan Maret hingga bulan April 2019. Penelitian dilaksanakan di provinsi Daerah Istimewa Yogyakarta melalui link googleform.

\section{Populasi dan Sampel Penelitian}

Populasi penelitian ini adalah pengguna media sosial yang berusia 18-25 tahun di Yogyakarta berjumlah 289.900 orang (BPS DIY). Sampel pada penelitian ini berjumlah 400 orang. Pengambilan sampel menggunakan teknik accidental sampling.

\section{Data, Instrumen, dan Pengumpulan Data}

Pengumpulan data pada penelitian ini menggunakan pengukuran dengan teknik kuesioner. Instrumen pengumpulan data yang digunakan berbentuk skala yang terdiri atas skala fear of missing out yang dimodifikasi dari skala fear of missing out milik Przybylski (2013) dan skala kesejahteraan psikologis yang dimodifikasi dari skala psychological well-being milik Ryff (1995).

Empat indikator fear of missing out yaitu kekhawatiran, kecemasan, ketakutan, dan keinginan untuk terus terhubung dengan orang lain. Individu yang memiliki fear of missing out yang tinggi ditandai dengan tingginya sikap yang menunjukkan indikator kekhawatiran, kecemasan, ketakutan, dan keinginan untuk terus terhubung dengan orang lain.
Kesejahteraan psikologis ditunjukkan oleh enam dimensi, yaitu dimensi penerimaan diri, relasi positif dengan orang lain, otonomi, penguasaan lingkungan, tujuan hidup, serta perkembangan diri. Individu yang memiliki tingkat kesejahteraan psikologis yang tinggi ditunjukkan oleh tingginya penerimaan diri, memiliki relasi positif dengan orang lain, otonomi yang tinggi, memiliki kemampuan penguasaan lingkungan, memiliki tujuan hidup yang terarah serta perkembangan diri yang baik.

\section{Teknik Analisis Data}

Teknik analisis data yang digunakan dalam penelitian ini terdiri atas analisis deskriptif, uji prasyarat analisis yang terdiri dari uji normalitas dan uji linearitas, serta uji hipotesis.

1. Analisis Deksriptif

Data yang berupa skala terdiri dari empat pilihan dengan skor masingmasing, yaitu (4) = sangat sesuai, (3) = sesuai, (2) = tidak sesuai, dan (1) = sangat tidak sesuai. Jumlah skor dari keseluruhan butir akan dikategorikan ke dalam lima kategori. Pengkategorian dilakukan dengan menggunakan perhitungan manual.

2. Uji Hipotesis

Pengujian hipotesis dalam penelitian ini menggunakan regresi sederhana dengan bantuan program komputer SPSS for Windows. Uji regresi sederhana dilakukan untuk mengetahui pengaruh satu variabel prediktor terhadap satu variabel kriterium. Uji regresi sederhana dipilih karena dalam penelitian ini terdiri dari satu variabel prediktor $(\mathrm{X})$ dan satu variabel kriterium $(\mathrm{Y})$. Untuk mencari persamaan garis regresi linear sederhana menggunakan rumus $\mathrm{Y}=\mathrm{a}+\mathrm{b}$.X.

\section{Hasil Penelitian dan Pembahasan}

Data penelitian diperoleh dari 400 orang berusia 18-25 tahun yang menggunakan media sosial. Data dikumpulkan menggunakan skala fear of missing out dan skala kesejahteraan 
psikologis. Analisis deskriptif dihitung dengan penghitungan manual berdasarkan norma kategorisasi Azwar (2012). Tabel 2 menunjukkan hasil kategorisasi dari variabel Fear of Missing out.

Tabel. 1 Kategorisasi Fear of Missing out

\begin{tabular}{lcc}
\hline Kategori & Rumus penentuan & Persentase \\
\hline Sangat & $>49$ & $5.5 \%$ \\
Tinggi & & \\
Tinggi & $43-49$ & $24.75 \%$ \\
Sedang & $35-42$ & $43.5 \%$ \\
Rendah & $28-34$ & $18 \%$ \\
Sangat & $<27$ & $8.25 \%$ \\
Rendah & & \\
\hline \multicolumn{3}{c}{ Total } \\
\hline
\end{tabular}

Berdasarkan Tabel 1 diketahui bahwa frekuensi paling banyak berada pada kategori sedang $(35-42)$ dengan presentase sebesar $43.5 \%$ dari jumlah sampel. Frekuensi paling sedikit berada pada kategori sangat tinggi $(\mathrm{X}>49)$ dengan presentase sebesar $5.5 \%$ dari jumlah sampel.

Tabel 2. Kategorisasi Kesejahteraan Psikologis

\begin{tabular}{lcc}
\hline Kategori & Rumus penentuan & Persentase \\
\hline Sangat & $>154$ & $7 \%$ \\
Tinggi & & \\
Tinggi & $140-154$ & $21 \%$ \\
Sedang & $124-139$ & $40 \%$ \\
Rendah & $108-123$ & $26 \%$ \\
Sangat & $<107$ & $6 \%$ \\
Rendah & & \\
\hline \multicolumn{3}{c}{ Total } \\
\hline
\end{tabular}

Berdasarkan Tabel 2 diketahui bahwa frekuensi paling banyak berada pada kategori sedang (124 - 139) dengan presentase sebesar $40 \%$ dari jumlah sampel. Frekuensi paling sedikit berada pada kategori sangat rendah $(\mathrm{X}<107)$ dengan presentase sebesar $6 \%$ dari jumlah sampel.

Hasil uji statistik $F$ menunjukkan nilai $F$ hitung sebesar 43.753 dengan probabilitas nilai sig, $0.001<\alpha(0.05)$ yang berarti variabel $\mathrm{X}$ dapat memprediksi variabel $\mathrm{Y}$. Koefisien determinasi $\mathrm{R}$ square menunjukkan hasil 0.099 yang berarti sumbangan efektif variabel $\mathrm{X}$ terhadap variabel Y sebesar 9.9\%.

Analisis data penelitian ini menunjukkan bahwa FoMO dapat menjadi prediktor kesejahteraan psikologis pada individu emerging adulthood pengguna media sosial. Hal ini berarti hipotesis yang berbunyi FoMO memiliki pengaruh terhadap kesejahteraan psikologis pengguna media sosial di usia emerging adulthood terbukti. semakin tinggi tingkat FoMO maka semakin rendah tingkat kesejahteraan psikologis pada individu emerging adult pengguna media sosial. Sebaliknya, semakin rendah tingkat FoMO maka semakin tinggi tingkat kesejahteraan psikologis pada individu emerging adult pengguna media sosial.

Faktor yang menyebabkan individu cenderung memiliki kesejahteraan psikologis yang rendah ketika memiliki FoMO dalam penelitian ini adalah dikarenakan penggunaan media sosial. Faktor lain yang juga turut memengaruhi kesejahteraan psikologis selain media sosial, sesuai dengan pendapat Huppert (2009) adalah tahap usia dan gender. Menurut Huppert (2009) perempuan kemungkinan memiliki kesejahteraan psikologis yang lebih rendah dibanding pria sehingga lebih mungkin memiliki mental disorder, sehingga mayoritas responden penelitian ini yang berjenis kelamin perempuan juga turut memengaruhi hasil kesejahteraan psikologis dan FoMO. Faktor lain yaitu usia, menurut Huppert (2009) bahwa skor kesejahteraan psikologis individu di usia pertengahan lebih rendah dibandingkan individu di usia muda maupun tua, sehingga subjek penelitian ini yang berada pada tahap emerging adulthood juga turut berpengaruh terhadap hasil kesejahteraan psikologis dan FoMO.

Individu yang mengalami FoMO cenderung merasakan stres hingga ketakutan ketika tidak dapat terhubung dengan media sosial (Beyens, dkk., 2016). Kecemasan tersebut kemudian memengaruhi kesejahteraan psikologis 
individu terutama dalam aspek penguasaan lingkungan, relasi positif dengan orang lain dan penerimaan diri (Beyens, dkk., 2016). Oleh karena itu, seseorang dengan tingkat FoMO tinggi cenderung memiliki kesejahteraan psikologis yang lebih rendah dibandingkan dengan orang yang tidak memiliki FoMO atau hanya memiliki tingkat FoMO rendah.

Masa emerging adulthood merupakan masa yang penting bagi individu untuk menyiapkan masa dewasanya (Arnett, 2000). Pada masa ini individu menghadapi tugas untuk membentuk relasi yang intim dengan orang lain (Erikson dalam Papalia, 2012). Oleh sebab itu, pada masa ini seseorang idealnya menjalin relasi dengan orang lain dan mengeksplorasi diri. Media sosial kemudian menjadi salah satu alat untuk memudahkan individu dalam menjalin relasi maupun mengeksplorasi diri. Namun, media sosial juga merupakan sarana bagi meluasnya fenomena FoMO yang harus diwaspadai.

Hasil penelitian ini menunjukkan bahwa individu pengguna media sosial terutama yang berada di masa emerging adulthood perlu menyadari potensi dampak negatif yang mungkin ditimbulkan akibat penggunaan media sosial yang tidak bijak. Penggunaan media sosial yang tidak bijak juga memiliki kontribusi dalam menurunkan tingkat kesejahteraan psikologis. Di sisi lain, kesejahteraan psikologis merupakan hal yang penting untuk dimiliki individu emerging adulthood dalam menyiapkan masa selanjutnya. Penggunaan media sosial yang tidak bijak dapat mengakibatkan individu kesulitan dalam menyiapkan masa dewasanya dengan keadaan sehat secara psikologis.

Hasil analisis menunjukkan bahwa variabel FoMO memiliki pengaruh negatif terhadap variabel kesejahteraan psikologis dengan sumbangsih sebesar 9,9\%. Hal ini menandakan bahwa ada pengaruh sebesar 9,9\% antara FoMO dengan kesejahteraan psikologis. Hal ini dikarenakan FoMO bukanlah faktor utama dalam pembentukan kesejahteraan psikologis, 90,1\% lainnya dipengaruhi oleh berbagai macam faktor; kepribadian (extraversion atau neuroticism); usia; gender; tingkat pendidikan; ketimpangan ekonomi; media sosial. FoMO merupakan bagian dari media sosial yang kemudian memberikan kontribusi terhadap rendahnya kesejahteraan psikologis. Dengan kata lain, FoMO dapat menjadi salah satu penyebab dari rendahnya kesejahteraan psikologis individu pengguna media sosial di masa emerging adulthood.

Hasil penelitian ini juga menunjukkan adanya hubungan antara FoMO dengan masing- masing dimensi dalam kesejahteraan psikologis. Hasil uji korelasi antara dimensi pada kesejahteraan psikologis dengan FoMO sebagai berikut:

Terdapat hubungan negatif dan signifikan antara FoMO dengan dimensi penerimaan diri. Hal ini sejalan dengan penelitian milik Beyens, dkk. (2016) yang menyatakan bahwa FoMO berhubungan dengan kecemasan dan orang dengan FoMO akan cenderung kesulitan dalam menerima dirinya. Orang dengan FoMO yang tinggi akan merasakan cemas ataupun khawatir terhadap kegiatan yang dilakukan oleh orang lain dan merasa bahwa hal yang dilakukan atau dimiliki oleh orang lain lebih menyenangkan dibandingkan dengan apa yang ia miliki atau alami. Dengan demikian, seseorang dengan FoMO yang tinggi dapat dikatakan tidak puas akan dirinya dan cenderung ingin menjadi orang lain.

Terdapat hubungan negatif dan signifikan antara FoMO dengan dimensi relasi positif dengan orang lain. $\mathrm{Hal}$ ini sejalan dengan penelitian milik Beyens, dkk. (2016) yang mengatakan bahwa individu dengan FoMO cenderung kesulitan dalam menjalani relasi yang positif dengan orang lain. Menurut Luckerson (2015) hal seperti ini terjadi karena dewasa ini, media sosial dan penggunaan internet mempengaruhi cara orang-orang dalam menjalani kehidupan terutama dalam

berkomunikasi. Luckerson

(2015) 
menambahkan bahwa belakangan ini, pertemuan- pertemuan yang seharusnya menjadi wadah bagi orang-orang untuk saling berinteraksi dan berbicara untuk membangun ikatan telah berubah menjadi pertemuan di mana kebanyakan orang justru lebih memilih untuk membuka media sosial melalui gawainya dibandingkan berinteraksi satu sama lain. Dengan kata lain, seseorang dengan FoMO yang tinggi lebih fokus terhadap apa yang terjadi di media sosialnya dibandingkan menjalin relasi yang lebih hangat dengan orang lain melalui pembicaraan langsung. Seseorang dengan FoMO berusaha untuk berkomunikasi dan terhubung dengan orang lain, namun tidak terjalin hubungan yang hangat, memuaskan, dan saling percaya dalam hubungan tersebut.

Terdapat hubungan yang negatif dan signifikan antara FoMO dengan dimensi otonomi. Seseorang dengan FoMO yang tinggi akan cenderung memiliki kemandirian yang rendah serta mudah terpengaruh oleh lingkungan sosial. Hal ini sejalan dengan penelitian FoMO di bidang ekonomi yang belakangan ini memanfaatkan perasaan FoMO untuk dapat menjalankan strategi penjualan yang efektif. Menurut Anggraini (2014), ketakutan akan tertinggal dari lingkungan sosial merupakan bentuk kebutuhan psikologis yang mampu memotivasi konsumen, untuk melakukan sesuatu yang mereka anggap bisa meredam ketakutan tersebut. Selain itu, seseorang dengan FoMO yang tinggi cenderung mencari penerimaan dan pengakuan dari orang lain dibandingkan mengevaluasi diri dengan standar pribadi. Hal ini berhubungan dengan kebutuhan untuk diterimayang kemudian menyebabkan orang dengan FoMO akan melakukan segala cara agar dapat diterima secara sosial. Hal ini didukung oleh hasil riset JWT Intelligence (2012) di mana 90\% responden mengaku senang menjadi orang yang paling mengetahui segala informasi, agar mereka dapat lebih diterima dan diakui di lingkungan sosialnya.

Terdapat hubungan yang negatif dan signifikan antara FoMO dengan dimensi penguasaan lingkungan. Hal ini sejalan dengan penelitian milik Reyes, dkk. (2018) yang mengatakan bahwa FoMO dapat menyebabkan munculnya Problematic Internet Use (PIU). Spada (2014) menjelaskan PIU sebagai ketidakmampuan individu untuk mengontrol perilakunya dalam penggunaan internet yang mana kemudian dapat mendatangkan konsekuensi yang tidak diinginkan. Seseorang dengan FoMO yang tinggi cenderung memiliki kemampuan penguasaan lingkungan yang rendah karena tidak memiliki kemampuan untuk menguasai dan mengatur lingkungannya (Ryff, 1995).

Terdapat hubungan yang negatif dan signifikan antara FoMO dengan dimensi tujuan hidup. Seseorang dengan FoMO yang tinggi cenderung tidak memiliki perasaan yang terarah dan tujuan dalam hidupnya. Hal ini sesuai dengan pernyataan Przybylski (2013) yang mengatakan bahwa seseorang dengan FoMO cenderung memiliki kepuasan yang rendah dalam pemenuhan kebutuhan dasar psikologisnya sehingga mereka hanya fokus dalam upaya pemenuhan kebutuhan tersebut.

Terdapat hubungan negatif dan signifikan antara FoMO dan perkembangan diri. Seseorang dengan FoMO yang tinggi cenderung sulit mengembangkan sikap atau perilaku baru untuk berkembang ke arah yang lebih baik. Hal ini sesuai dengan penelitian milik Alt (2015) yang menemukan bahwa seseorang dengan FoMO yang tinggi cenderung tidak memiliki motivasi untuk belajar.

\section{Simpulan dan Saran}

\section{Simpulan}

Berdasarkan penelitian yang telah dilakukan, dapat diambil kesimpulan 
bahwa ada hubungan negatif antara Fear of missing out (FoMO) dengan kesejahteraan psikologis pada pengguna media sosial di tahap usia emerging adulthood di DIY. Hal ini berarti ketika seseorangmemiliki tingkat FoMo yang rendah, maka ia akanmemiliki kesejahteraan psikologis yang cenderung tinggi. Sebaliknya, ketika seseorang memiliki tingkat FoMO yang tinggi, maka ia akan memilikikesejahteraan psikologis yang cenderung rendah.

\section{Saran}

Berdasarkan kesimpulan dari penelitian yang sudah dilakukan, maka saran yang dapat diberikan yaitu sebagai berikut:

1) Bagi pengguna media sosial, diperlukan penggunaan media sosial secara bijak. Penggunaan media sosial secara bijak misalnya dengan; memilah informasi yang bermanfaat dan tidak menjadikan media osial sebagai alat utama dalam berkomunikasi.

2) Bagi peneliti lain, diperlukan pengambilan sampel yang lebih proporsional agar lebih menggambarkan keadaan yang sesungguhnya.

\section{Daftar Pustaka}

Azka, F., Firdaus, D.F., \& Kurniadewi, E. (2018). Kecemasan sosial dan ketergantungan media sosial pada mahasiswa. PSYMPATHIC: Jurnal Ilmiah Psikologi Vol. 5, No.2, 2018: 201-210.

Beyens, I., Frison, E., \& Eggermont, S. (2016). 'I don't want to miss a thing': adolescents' fear of missing out and it's relationship to adolescents' social needs, facebook use, and facebook related stress. Computers in Human Behavior, 64, 1-8.

Boyd, D.M. \& Ellison, N.B. (2008). Social Networks sites: definition, history, and scholarship. Journalof ComputerMediated Communication, 3, 210-230.
Burke, M., Marlow, C., \& Lento, T. (2010). Social network activity and social well- being. Postgraduate Medical Journal, 86, 455-459.

Huppert, F. A. (2009). Psychological wellbeing: evidence regarding its causes and consequences. Applied Psychology: Health and Well-Being, 1(2), 137-164.

Lenhart, A. (2015). Teens, social media and technology overview. Washington DC: Pew Internet \& American Life Project.

Luckerson, V. (2014). Fear, misinformation, and social media complicate Ebola fight. Time. Diakses dari http://time.com/3479254/ebolasocial- media/

Luna, K. (2014). The psychology of fomo. Diambil dari: youbeauty.com/lifethepsychology-of- fomo/

Oberst, U., Renau, V., Chamarro, A., \& Carbonell,

X. (2016). Gender stereotypes in facebook profiles: are women more female online?. Computers in Human Behavior, 60, 559-564. Papalia, D.E., Olds, S.W., \& Feldman, R.D. (2007). Human development 10th ed. New York:McGraw Hill Companies.

Przybylski, A.K., Muryama, K., DeHaan, C.R., \& Gladwell, V. (2013). Motivational, emotional, and behavioral correlates of fear of missing out. Computers in Human Behavior, 29, $1841-1848$

Putra, A.D. (2018). Hubungan antara fear of missing out dengan kesejahteraan psikologis pengguna instagram pada masa transisi menuju dewasa. Skripsi, Diterbitkan, Universitas Sanata Dharma, Yogyakarta. 
Reyes, M.E.S. \& Cayubit, R.F.O. (2018). Fear of missing out and its link with social media and problematic internet use among Filipinos. North American Journal of Psychology

RSPH. (2017) Social media and young people's mental health and well being. Diambil dari: https://www.rsph.org.uk/orgwork/policy/social-media-andyoung.

JWT Intelligence. (2012). Fear of missing out (fomo). Diakses dari http://www.jwtintelligence.com/wp content/uploads/2012/03F_JWT_F oMO_u pdate_3.21.12.pdf.

Kesehatan, K., \& RI, K. K. (2013). Riset kesehatan dasar. Jakarta: Badan Penelitian dan Pengembangan Kesehatan Departemen Kesehatan republik Indonesia. people-s- mental-health-andwellbeing.html

Ryff, C.D. (1989) Happiness is everything, or is it? explorations on the meaning of psychological well being. Journal of Personality and Social Psychology, 57(6), 1069.(1995).

Psychological well-being revisited: advances in the science and practice of eudaimonia. Psychotherapy and Psychosomatics, 83, 10-28.

Ryff, C.D., \& Singer, B. (2002). From social structure to biology. Handbook of Positive Psychology, 63-73.

Salkind, N.J. (2010). Encyclopedia of human development. USA:Sage Publications, Inc. Publication Vol. 1 No. 05-5727.

Shapiro, L.A.S., Margolin, G. (2013). Growing up wired: social networking sites and adolescent psychosocial development. Clinical Child and Family Psychology Review, 17(1).

Spada, M. (2014). An overview of problematic internet use. Addictive Behaviors, 39(1), 3-6.

Sugiharto, B.A. (2016). Pengguna internet di indonesia didominasi anak muda. CNN Indonesia. Diambil dari:http://cnnindonesia.com/tekn ologi/20161 024161722-185167570/pengguna- internet-diindonesia-didominasi-anak- muda

Twenge, J.M., Martin, G.N., \& Campbell, W.K. (2018). Decreases in psychological well- being among American adolescent and links to screen time during the rise of smartphone technology. Emotion, 18(6), 765-780.

Amir \& Trianasari. (2013). Pola komunikasi antarpribadi dalam pengasuhan anak: Kasus orang tua beda agama (Interpersonal communication patterns in parenting: The case of parents with different religion). Jurnal Komunikasi KAREBA, 2(1)

Andri, Winarti, \& Utami. (2001). Pola asuh orangtua dan nilai-nilai kehidupan yang dimiliki oleh remaja. Fenomena: Jurnal Psikologi, 71-101

Auliarahma. (2015). Hilangnya kedudukan nilai- nilai pancasila dalam kehidupan masyarakat. Tugas. STMIK AMIKOM Yogyakarta

Barni, Daniela, et al. (2011). Value transmission in the family: do adolescents accept the values their parents want to transmit? Journal of Moral Education, 40 (1), 105-121

Chan, H.-W., \& Tam, K.-P. (2016). Understanding the lack of parentchild value similarity: The role of 
perceived norms in value socialization in immigrant families. Journal of Cross-Cultural Psychology, 47(5), 651-669.

https://doi.org/10.1177/002202211 6635744.

Davis, A. (2010). Defending religious pluralism for religious education. Ethicsand Education, 5 (3), 189-202.

De Muynck, B., Vos, P., Hoogland, J., \& Van der Stoep, J. (2017). A Distinctive of Christian Higher Education: Educating for Vocation. Christian Higher Education, 16 (1-2), 310.

Friedman. (2010). Keperawatan keluarga. Yogyakarta: Gosyen Publishing.

Hurlock, Elizabeth B. (1980). Psikologi perkembangan: suatu pendekatan sepanjang rentang kebidupan. Jakarta: Gramedia.

Imron, A. (2012). Proses manajemen mutu sekolah dasar berbasis relegi. Jurnal Sekolah Dasar. 21(2):27-38.

Knafo, Ariel \& Schwartz, Shalom. (2009). Accounting for parent-child value congruence: theoretical considerations and empirical evidence. In U. Schönpflug (Ed.), Culture and psychology. Cultural transmission: Psychological, developmental, social, and methodological aspects (pp. 240-268). New York, NY, US: Cambridge University Press.

Lestari, Sri. (2014). Psikologi keluarga penanaman nilai dan penanganan konflik dalam kelwarga. Jakarta: Kencana Prenada Media Group.

Min, Joohong, Silvester, Merrin \& Lendon, Jessica. (2012). Intergenerational transmission of values over the family life course. Advances in Life Course Research, 17(3), 112-120.
Rokeach, M. (1973). The nature of human values. New York: Free Press.

Rosmawaty. (2010). Mengenal ilmu komunikasi. Jakarta: Widya Padjadjaran

Sari, Yunu M. (2014). Pembinaan toleransi dan peduli sosial dalam upaya memantapkan watak kewarganegaraan (civic disposition) siswa. Jurnal Pendidikan Ilmu Sosial, Volume 23 No. 1, Edisi Juni 2014.

Seligman, C., Olson, J. M., \& Zanna, M. P. (Eds.). (2013). The Ontario symposium on personality and social psychology, Vol. 8. The psychology of values: The Ontario symposium, Vol. 8. Hillsdale, NJ, US: Lawrence ErlbaumAssociates, Inc.

Sjarkawi. (2008). Membentuk kepribadian anak "Peran moral intelektual, emosional, dan sosial sebagai mujud integritas membangun jati diri”. Jakarta: PT. Bumi Aksara.

Smith, J. A., Flowers, P., \& Larkin, M. (2009). Interpretative Phenomenological Analysis. London: SAGE Publication.

Storm, I. and D. Voas. (2012). The Intergenereational transmission of religious service attendance". Nordic Joumal of Religion and Society, 25 (2): $131-150$ 